\title{
Puffing/Micro-explosion in Composite Mono- and Multi-component Droplets: Experimental Results and Modelling
}

\author{
Roman Fedorenko ${ }^{1}$, Dmitrii Antonov ${ }^{1}$, Pavel Strizhak ${ }^{1}$, Elena Shchepakina ${ }^{2}$, Vladimir Sobolev², \\ Sergei S. Sazhin ${ }^{3}$ \\ ${ }^{1}$ National Research Tomsk Polytechnic University, 30 Lenin Avenue, Tomsk, 634050, Russia \\ vfedrm@gmail.com; antonovdv132@gmail.com; pavelspa@tpu.ru \\ ${ }^{2}$ Samara National Research University, 34, Moskovskoye Shosse, Samara, 443086, Russia \\ shchepakina@yahoo.com; hsablem@gmail.com \\ ${ }^{3}$ Advanced Engineering Centre, University of Brighton, Brighton, BN2 4GJ, UK \\ S.Sazhin@brighton.ac.uk
}

\section{Extended Abstract}

The results of recent experimental studies of puffing and micro-explosion and modelling approaches to their analysis are summarised. In [1] the analysis was focused on non-mixed and premixed Diesel fuel/water and rapeseed oil/water droplets. Air temperature was in the range $850-1100^{\circ} \mathrm{C}$, and initial droplet radii were in the range $0.62-1.34 \mathrm{~mm}$. It was shown that the time to puffing/micro-explosion decreases with increasing temperature, is weakly dependent upon the volume fraction of fuel, and increases with increasing droplet sizes. The analysis described in [2] focused on detailed experimental investigation of puffing and micro-explosions in composite water/rapeseed oil droplets in the presence of lignite and bituminous coal micro-particles in water. Droplets with radii in the range 1-2 mm were placed in a hot chamber with air velocities $3-7 \mathrm{~m} / \mathrm{s}$ and temperatures up to $600^{\circ} \mathrm{C}$. The time to puffing/micro-explosion and average radii of child droplets generated during puffing and micro-explosions were shown to decrease with increasing gas temperature. The abovementioned experimental results were analysed using a model described in [3]. This model assumes that a spherical water sub-droplet is located in the centre of a spherical fuel droplet. The heating of a fuel droplet is described by the heat conduction equation with the Robin boundary condition at its surface and continuity conditions at the fuel-water interface. The analytical solution to this equation, obtained at each time step, was incorporated into the numerical code and used for the analysis of droplet heating and evaporation. The effects of droplet thermal swelling were considered. The results of calculations using this code allowed the authors of [3] to obtain the time evolution of the temperature at the water/fuel interface $\left(T_{w}\right)$ and the time evolution of $\mathrm{d} T_{w} / \mathrm{d} t$. The latter derivative was used for the estimation of the water nucleation temperature at the water/fuel interface. It was assumed that puffing/micro-explosion starts when the temperature at this interface is equal to the water nucleation temperature. This model was generalised in [2] in a non-self-consistent way to consider the relative motion of droplets. More recently, the models described in $[3,2]$ were generalised to consider the multi-component composition of fuel, using the analytical solution to the equation for species diffusion incorporated into the numerical code. Work on this extended abstract was supported by the National Research Tomsk Polytechnic University (project VIU-ISHFVP-60/2019) (P. Strizhak; planning of the experiments), Scholarships from the President of the Russian Federation (Grants SP-447.2021.1 and MN-7/2260) (D. Antonov and R. Fedorenko; performing the experiment, and applications of the models), and the Russian Science Foundation (Grant 21-19-00876) (E. Shchepakina, V. Sobolev, S. Sazhin; development of the models, including analytical solutions).

\section{References}

[1] D.V. Antonov, G.V. Kuznetsov, P.A. Strizhak, O. Rybdylova, S.S. Sazhin, "Micro-explosion and autoignition of composite fuel/water droplets", Combust. Flame, vol. 210. pp. 479-489, 2019.

[2] D.V. Antonov, P.A. Strizhak, R.M. Fedorenko, Z. Nissar, S.S. Sazhin, "Puffing and micro-explosions in rapeseed oil/water droplets: the effects of coal micro-particles in water", Fuel, vol. 289. 119814, 2021.

[3] S.S. Sazhin, T. Bar-Kohany, Z. Nissar, D. Antonov, P. Strizhak, O. Rybdylova, "A new approach to modelling microexplosions in composite droplets", Int. J Heat Mass Transfer, vol. 161, 120238, 2020. 